\title{
Evaluating the Burden of Job Stress From the Public-Health and Economic Viewpoints:
}

\author{
Perspectives and Methodological Pitfalls
}

Le poids imputable à l'exposition au stress au travail en termes économiques et de santé publique : enjeux et écueils méthodologiques

Hélène Sultan-Taïeb and Isabelle Niedhammer

\section{(2) OpenEdition}

\section{Journals}

\section{Electronic version}

URL: http://journals.openedition.org/travailemploi/6295

DOI: 10.4000/travailemploi.6295

ISSN: $1775-416 \mathrm{X}$

\section{Publisher}

DARES - Ministère du Travail

\section{Printed version}

Date of publication: 15 December 2013

Number of pages: $45-54$

ISSN: 0224-4365

\section{Electronic reference}

Hélène Sultan-Taïeb and Isabelle Niedhammer, «Evaluating the Burden of Job Stress From the PublicHealth and Economic Viewpoints: », Travail et Emploi [Online], Hors-série | 2013, Online since 01 January 2014, connection on 01 May 2019. URL : http://journals.openedition.org/travailemploi/6295 ; DOI : 10.4000/travailemploi.6295 


\title{
Evaluating the Burden of Job Stress From the Public-Health and Economic Viewpoints: Perspectives and Methodological Pitfalls ${ }^{*}$
}

\author{
Hélène Sultan-Taïeb ${ }^{(* *)}$, Isabelle Niedhammer ${ }^{(* *)}$
}

The evaluation of the burden of job stress on both the number of cases of diseases (morbidity and mortality) and the resulting economic costs are key questions in public health. However, work in this area remains only very sparse. We here underline the importance of such a calculation, and briefly present a feasible estimation method (that of attributable fractions) and its limitations. This method uses epidemiological data on the relative risk of disease associated with a given job stress risk factor, and the prevalence of exposure to this factor. The associated difficulties revolve around the need for robust and consistent epidemiological data from prospective large-sample etiological studies. The resulting estimates of the evaluation of the burden of job stress provide useful information for decision-making regarding the allocation of resources for prevention purposes.

Work intensity in France rose considerably over the 1990s and at the beginning of the 2000s (Parent-Thirion et al., 2007; Gollac, Volkoff, 2006; Askenazy, 2005; Volkoff, 2008). This phenomenon is one potential explanation of the increase in exposure to psychosocial risks at work. Amongst the existing psychosocial risk models, such as work-related violence, organisational injustice (NDJABouÉ et al., 2012) and job insecurity, job stress (as in the models of Karasek, 1998, and Siegrist, 2004) plays a role both as a part of general work conditions and in its own right in the academic literature (NiedHAMmer, 2011). French data is available on exposure to job stress as formulated in Karasek's model, which defines job strain as a combination of high psychological demands at work (in terms of task quantity and complexity, and time pressure) and low decision latitude, where this latter covers both decision authority and skill discretion (KARASEK, 1979; KARASEK, THEORELL, 1990): see Box 1. These results come from the 2003 SUMER survey (SUrveillance MÉdicale des Risques professionnels: see Box 2), which is nationally representative of employees (GUIGNON, 2001). Women are found to be substantially more

(*) Article published in French in Travail et emploi, $\mathrm{n}^{\circ}$ 129, janvier-mars 2012.

(**) Université du Québec à Montréal (UQÀM) ; Centre de recherche interdisciplinaire sur la biologie, la santé, la société et l'environnement (Cinbiose), Québec; Laboratoire d'économie gestion (UMR CNRS 5118), université de Bourgogne, France; sultan_taieb.helene@uqam.ca

$(* * *)$ Institut national de la santé et de la recherche médicale (Inserm), U1018, Centre de recherche en épidémiologie et santé des populations (CESP) ; isabelle.niedhammer@inserm.fr exposed to job stress as defined by Karasek than are men $(28.2 \%$ and $19.6 \%$, respectively). There is also a notable occupational gradient, with those in the least-skilled occupations (clerks/service workers and manual workers) being more exposed than those in other occupations (NIEDHAMMER et al., 2007; NiedHAMmer et al., 2008; NiedHAMmer et al., 2006).

The measurement of occupational-stress exposure is important for public health, as the epidemiological literature has established the association between such exposure and a number of health outcomes. The epidemiological literature has underlined an association between job stress in the Karasek model and cardiovascular disease (KIVIMAKI et al., 2006; BELKIC et al., 2004; De LANGe et al., 2003) and anxiety and depressive syndromes (STANSFeld, CANDY, 2006; Bonde 2008), and, to a lesser extent, a number of musculoskeletal disorders (MSDs: Bongers, 2002, 2006). However, there is only little work on the burden of job stress: a few papers have evaluated the effect of job stress in terms of number of cases (morbidity and mortality) and economic burden, such as Ramacciotti and Perriard (2001) in Switzerland, LeVI and Lunde-Jensen (1996) in Sweden, Norway and Denmark, and BÉJEAN and Sultan-TAÏ̈B (2005) in France.

In this article we emphasise the importance of carrying out such calculations, and then present a feasible estimation method (that of attributable fractions) and its associated limitations. 


\section{Box 1 \\ The Karasek Model}

The Karasek questionnaire is the main instrument used to evaluate the presence of job stress. In the model set out by Karasek, the two principal dimensions are psychological job demands and decision latitude. The former refers to the quantitative and qualitative aspects of the workload. Decision latitude covers two sub-dimensions: skill discretion and decision authority. These are defined by the possibility of using and developing one's skills and qualifications at work for the first, and room for manoeuver in the way in which the job is carried out and participation in relevant decisions for the second. In the Karasek model, situations of high psychological demands and low decision latitude (job strain) produce health risks. The recommended questionnaire based on the Karasek model includes 18 items for the measurement of these two dimensions: nine for psychological demands, and nine others for decision latitude (six on skill discretion and three for decision authority). The possible replies to these 18 questions are presented on a Likert scale: "Completely Disagree", "Disagree", "Agree" and "Completely Agree". The items covering job demands and decision latitude are then aggregated to produce two scores, which latter are then dichotomised according to their median values in the sample in order to construct the job strain variable (defined as high job demands but low decision latitude).

\section{An Estimation Approach in the Context of French Reforms}

The estimation of the number of cases of illness resulting from job stress is one way of evaluating the social cost of this risk factor in terms of morbidity and mortality, and potentially, if the data are available, to consider the social inequality in health attributable to this factor. The existing literature has suggested that the social gradient observed between socio-economic status and health may well be partly attributable to different exposures to job stress (AlDABE et al., 2011). These results, across Europe globally and in a certain number of specific European countries, have been confirmed in the rare contributions covering workers in France: workrelated factors, including job stress, account for between $24 \%$ and $58 \%$ of social-health inequalities, and between $31 \%$ and $74 \%$ of the social inequality in mortality (NIEDHAMMER et al., 2008; NiEDHAMMER et al., 2011). Work-related factors do not necessarily have the same effect for men and women, across the different occupations, and according to the health variable under consideration. For example, the classic exposures (physical and chemical exposures) seem to play a more important role in explaining the differences in health outcomes between manual workers and managers, while job stress is a more relevant determinant of the differences between clerks/service workers and managers (Niedhammer et al., 2008).

\section{Box 2}

\section{The SUMER 2003 National Survey}

SUMER is a periodical national cross-sectional survey carried out jointly by the Direction de l'animation de la recherche, des études et des statistiques (Dares) and the Direction générale du travail (DGT) from the French Ministry of Labour, together with a regional network of volunteer occupational physicians. The main aim of SUMER is to draw up a map of work-related health and safety risks for French employees. The population covered by the 2003 survey is all private-sector and agricultural workers, as well as workers in public hospitals, the publicsector electricity and gas companies (EDF-GDF), the Post Office, National Rail (SNCF), and Air France. Workers in some sectors are not represented in the survey, in particular those in public administrations (apart from those in hospitals), as well as those in the mining sector, shipping and urban transport, and employees of France Télécom.

The protocol followed was that the volunteer occupational physicians randomly drew survey participants from the population of employees who periodically have health check-ups. The occupational physician (who carries out these periodical check-ups) filled out the main survey questionnaire for each randomly-chosen subject, and half of the latter were asked to fill out a self-completion questionnaire before their check-up, which was then to be handed over to the physician at the check-up. Both questionnaires were rendered anonymous, although the two (that of the individual and that filled out by his or her physician) could be linked together via an identification number printed at the top of both surveys. Only the occupational physician retained the list of the employees who appear in the survey. The survey was approved by the Commission on Information Technology and Liberties (known by its French acronym as the Cnil). The questions referring to the Karasek model appeared in the self-completion part of the survey. The 2003 SUMER survey covered 49,984 employees, with the self-completion questionnaire being proposed to 25,380 of them. Of the latter, 24,486 agreed to participate $(14,241$ men and 10,245 women), yielding an overall response rate of $96.5 \%$.

The SUMER survey was carried out again in 2010 , but the results of the survey have not yet been statistically analysed in detail.

The evaluation of the cost of illness attributable to job stress also helps us to put a figure on the economic cost in terms of health expenditures incurred both by the public-health system and by individuals as out-of-pocket payments. These costs also include the loss of production resulting from 
workplace absence and presenteeism. Intangible costs (pain, suffering, reduced quality of life and so on) are also a category of costs that should be taken into account. Estimated costs can be calculated from different perspectives: that of the social-security system, that of the employee, or from the point of view of society as a whole as revealed by the overall effect on social welfare.

Having such information is central in order to establish priorities in terms of prevention policy. In general, workplace health and safety policies will affect employees' exposure to risk, but such programmes often operate with only relatively limited resources. Being able to put a figure on the cost of job stress will likely enable better decisions to be made about the resources that should be made available to prevention programmes (SERRIER et al., 2010).

This issue is currently at the heart of French preoccupations. In July 2008, a national agreement on job stress was signed by employer and worker representatives, which is an application at the national level of the European framework agreement of October $8^{\text {th }} 2004$. A second agreement was signed on March $26^{\text {th }} 2010$ regarding workplace harassment and violence, supplementing the 2008 agreement and modifying the agreement signed at the European level on December $15^{\text {th }} 2006$. At the same time, in the framework of the emergency plan for the prevention of job stress, launched in October 2009, the Labour Minister Xavier Darcos asked firms with more than 1000 employees to sign agreements regarding the prevention of job stress. In April 2011, the Advisory Board for Working Conditions (Conseil d'orientation des conditions de travail: COCT) carried out a review of the 600 agreements and action plans signed since 2009, which figure reflects that the phenomenon has been taken into account by firms, even though some of these agreements refer to the diagnostic and evaluation stage of job stress, without specifying any particular plan of action (DIRICQ, 2011). At the same time, the need for a concerted programme of preventative measures at the workplace was emphasised in a number of different reports, sponsored by the Senate (DÉRIOT, 2010) and the Prime Minister (Lachmann et al., 2010). The emergency plan for the prevention of job stress also led to the setting-up in 2009 of an expert panel for the statistical measurement of job stress, chaired by Michel Gollac. The task of this panel was to make proposals for the establishment of a national survey measuring exposure to job stress. The ensuing report produced by the panel underlined the difficulty of establishing a single indicator of such stress, and the interest of taking into account the multidimensional character of exposure in any measurement instrument (Gollac, BODIER, 2011).

These developments reflect the will to instigate prevention programmes based on accurate information on the exposure to job stress in France. This detailed information will allow the groups most at risk to be identified, both in terms of occupation and industry, and to evaluate the relative importance of the different dimensions of job stress. The estimations of the burden of diseases attributable to job stress exposure follow the same objectives. These estimations also yield an indicator of the distribution of the reimbursement of diseases by the different branches of the social security system. The conclusions of the Diricq Commission (DIRICQ, 2008,2011 ) thus determined the amount reimbursed by the occupational illnesses and injuries branch of the social security system to the health insurance branch. This aimed to cover expenditure on cases which are imputable to the occupational illnesses and injuries branch but not recognised as such.

In general, putting a number on illnesses which can be attributed to work-related exposures runs into a number of difficulties, and in particular with respect to data availability. At the national level, data on occupational illnesses and injuries from the Cnam-TS (the National Health Insurance Fund for Employees) provide an incomplete picture due to the phenomenon of under-declaration (THÉBAUDMony, 2007; Daubas-Letourneux, 2008) and under-recognition (KASBI-BENASSOULI et al., 2005; DIRICQ, 2011), which leads to the invisibility of a number of cases (Gollac, VolKOFF, 2006; THÉBAUDMony, 2006). For example, the number of cases of lung cancer resulting from exposure at work was estimated to be between 2713 and 6051 in 1999 (IMBERNON, 2003). However, in the same year, only 458 cases of lung cancer were recognised and reimbursed by the occupational illnesses and injuries branch. With respect to MSDs, the rate of underdeclaration of carpal tunnel syndrome was estimated at about 46\% in France in 2003 (DIRICQ, 2008, based on the results in RoQuelaure et al., 2005). This is far from being a French specificity, as the results in the Quebec survey on work, employment and health conditions, and job security (Enquête québécoise sur les Conditions de travail, d'emploi et de santé et de sécurité au travail: EQCOTESST) show. This representative survey of the active working population, administered by telephone, was carried out in 2007-2008. The survey results (see VézINA et al., 2011, p. 496) show that fewer than one in five employees who suffered from a MSD that they attributed to their work and which had led to a work absence had declared this fact to the Commission for Work Health and Security in Quebec (Commission de la santé et sécurité du travail au Québec: CSST).

This invisibility of work-related illnesses and injuries leads to the under-estimation of the prevalence of different pathologies, and therefore of the importance of the various risk factors that might be behind them. This in turn leads to an under-estimation of the benefits that would accrue to prevention policies reducing the prevalence of these risk factors. 


\section{The Method of Attributable Fractions}

The method of attributable fractions (AF) is frequently used in public health to estimate the association between exposure to a risk factor and individual health. In the domain of environmental health, for example, the link between atmospheric pollution and asthma is estimated; in behavioural health, it could be the association between health and smoking (Jeanrenaud, Soguel, 1999) or drug use (Kopp, Fenoglio, 2003). This method is equally appealed in the domain of health and job security (Driscoll et al., 2005; Nelson et al., 2005; LaMontagne et al., 2008; Nurminen, KarJalainen, 2001).

Attributable fractions yield an estimation of the fraction of pathology cases which are "attributable to an exposure in a population and that would not have been observed if the exposure had been non-existent" (Nurminen, KarJalainen, 2001). This calculation uses two types of data: the prevalence of exposure $\mathrm{P}_{\mathrm{e}}$ in the whole population (the proportion of the population which was exposed to the risk factor) and the relative risk RR (which is the ratio between two risks of illness or death, one for those who were exposed to the risk factor and the other for those who were not), from prospective surveys (LeVIN, 1953).

The following formula is used to estimate the attributable fractions AF based on adjusted RRs, that is values of RR which take into account various potential adjustments and/or confounding factors.

$$
\mathrm{AF}=\mathrm{P}_{\mathrm{e}}(\mathrm{RR}-1) /\left(1+\mathrm{P}_{\mathrm{e}}(\mathrm{RR}-1)\right)
$$

Confounding factors are defined as those variables which modify the association under consideration between exposure and illness, either positively or negatively. For example, the association between job stress and cardiovascular disease is often estimated taking confounding factors such as smoking into account. Controlling for such factors is an issue of great importance in etiological epidemiology.

A certain number of criteria have to be satisfied in order for attributable fractions to be used (ROTHMAN, Greenland, 1997, cited by Nurminen, KarJaLAinen, 2001): the strength of the association, the presence of a dose-response relationship, the specificity of the association, the consistency of the results, and the existence of a causal relationship identified in the literature (see below for a general discussion of the use of this method). With respect to this last criterion, many authors agree that if a causal relationship seems to exist thanks to a body of convergent hypotheses, even without having been demonstrated with a strict degree of certainty, then the use of attributable fractions remains justified
(WALter, 1998; Wilson et al., 1998; BENICHOU et al., 1998 cited by Nurminen, Karjalainen, 2001).

The method produces an estimate of the attributable fraction which is thus not established individually on the basis of an etiological clinical diagnosis. Even though these fractions only produce an estimation of the percentage of illnesses which are due to work-related risk factors, they remain an extremely useful tool for the estimation of the economic cost of illness which can be assigned to different risk factors (BARNAY et al., 2010). Economic analyses based on this method remain however only limited as of present.

\section{Estimating Attributable Fractions for Job Strain in France}

The Occupational and Environmental Health Programme of the French National Research Agency (Agence nationale de la recherche) financed research aiming to estimate the fractions of cardiovascular disease, depression and anxiety, and MSDs attributable to exposure to Karasek-type job strain in France (Sultan-Taïeb et al., 2011).

The data on the prevalence of exposure came from the national 2003 SUMER survey (see Box 2 above and GUIGNON, 2001), with a prevalence rate of $19.6 \%$ for men, $28.2 \%$ for women, and $23.2 \%$ overall.

There is a lack of French data regarding the relative risk of different pathologies due to job strain. We therefore turn to data on relative risks from a review of the international epidemiological literature, and more precisely that from developed countries. For this review, we retained studies which satisfied the following criteria: the analysis had to be prospective (or in panel), published in refereed academic journals between 1990-2008, with a sample size of over 100, an exposure measure based on a combination of the two dimensions of job strain with more than one item by dimension (decision latitude and job demands), either clinically-measured health effects (cardiovascular disease) or via standardised instruments (syndromes of depression or anxiety, MSDs), with a statistical analysis which allows the estimation of relative risks adjusted for potential confounding factors.

We were able to identify thirteen studies fulfilling these criteria with respect to cardiovascular disease, seven for depression/anxiety, and eleven for MSDs. Details regarding these studies can be found in Sultan-TAïeB et al. (2011). The studies under consideration are mostly from Northern Europe; there is only one French study. These are all prospective analyses, the sample is followed over time and the goal is to examine the incidence (in terms of new cases) of illness over the retained time period, 
and the individuals in the sample did not suffer from the disease at baseline. This type of prospective protocol is particularly important in epidemiology for the evaluation of etiological analyses. Recall bias is minimised, as is the possibility of reverse causality between exposure and illness. The studies in our review cover large samples, with over 1000 respondents for the most part and a certain number including over 10000 respondents. General surveys of employees are relatively rare, and most of the samples cover particular occupations or industries: nurses, metal workers, white-collar workers, dentists, train or bus drivers, or manual workers. The type of illness also varies. Studies on cardiovascular disease cover all types of cardiovascular diseases including coronary heart diseases (CHD), myocardial infarction (MI) and angina. Studies on psychological illness mostly refer to measures of depression or anxiety. Musculoskeletal disorders variously cover the back, shoulder, neck, arm, hand and so on. Last, the confounding variables taken into account also differ between analyses, with only few variables being almost systematically controlled for (the exceptions being age and biomechanical exposure, in eight out of the eleven articles considering MSDs).

The results from this review suggest a relative risk (RR) of cardiovascular disease or death resulting from job strain of between 1.26 and 2.4 for men, and between 0.63 and 1.67 for women (both RR estimates being non significant for women). For depression and anxiety, the RR for job strain varies between 1.58 and 3.3 for men, and between 1.2 and 2.8 for women. Last, the results for MSD yield figures between 0.94 and 2.3, for various different types of disorders. However, only six RR out of 19 are significant for this type of illness, suggesting only a limited etiological relation between job strain and these types of illness. More details on the studies included in this review are available in Sultan-Taïeb et al. (2011). The largest confidence intervals result when either the sample or the number of cases of illness are small, reflecting more imprecise estimates. The analysis of cardiovascular disease in UCHIYAma et al. (2005) concerns only a small number of cases; so small for women (only nine cases) that we did not include the results in our review. Equally, for psychological illness, the three RR estimates based on evaluations using a standardised diagnostic instrument (the Composite International Diagnostic Interview -CIDI) are based on far fewer diagnosed cases than the number of symptomatic cases appearing in other work based on self-reported scales such as the General Health Questionnaire (GHQ) or the Center for Epidemiologic Studies Depression questionnaire (CES-D) for example. It is also notable that it is the largest estimates of RR that have the widest estimated confidence intervals, again suggesting greater imprecision in the estimates.

Table 1 shows the brackets of resulting attributable fractions by illness and gender using the formula presented above. The high range value of these fractions reaches $25 \%$ for cardiovascular disease, $34 \%$ for anxiety and depression, and 27\% for MSDs. We cannot exclude the possibility that these fractions are zero for female cardio-vascular illness, as well as for MSDs.

\section{Inherent Limits from Data Availability in the Literature}

The articles appearing in our literature review make a certain number of hypotheses and suffer from limitations, to which it is useful to return. First, the data do not come from the same country, nor from the same occupation and industry. As such, we have to make the hypothesis that there are no industrial, occupational or geographic particularities in these relative risks. In addition, the number of illnesses that can be evaluated is limited by data availability, and we have only considered one measure of job stress: that of job strain, as in the Karasek model. Last, other types of heterogeneity between the articles that we have considered are likely to have affected our attributable fractions results.

The data available for the estimation of relative risks used here mostly is not French. However, the estimations here do use relative risk data which for the most part come from countries with development levels that are similar to France (NuRMINEN, KarJaLAinen, 2001, p. 165). As such, the extrapolation of these numbers to France may not introduce major bias. However, the data used in the studies in our literature review did not all come from

Table 1: Fractions of Cardiovascular Diseases, Anxiety/Depression and Musculoskeletal Disorders Attributable to Job Strain in France in 2003

\begin{tabular}{|l|c|c|c|}
\hline \multicolumn{1}{|c|}{ Illness } & Men & Women & Whole Population \\
\hline Cardiovascular disease & & & \\
Morbidity & $4.9-21.5 \%$ & $0-15.9 \%$ & $6.5-25.2 \%$ \\
Mortality & $7.9-21.5 \%$ & $2.5 \%$ & $6.5-25.2 \%$ \\
\hline Anxiety and Depression & $10.2-31.1 \%$ & $5.3-33.6 \%$ & $6.5 \%$ \\
\hline MSDs (various localisations) & $0-19.6 \%$ & $0-26.8 \%$ & $3.4-19.9 \%$ \\
\hline
\end{tabular}

Source: Sultan-Taïeb et al., 2011. 
nationally-representative samples, or even from a wide range of occupations and industries. Given the limited coverage of this data, we have to make the hypothesis that the effects of job strain on the different illnesses considered here are similar across industry and occupation, which hypothesis is not currently established. For the latter, we would require a greater amount of good-quality data on estimated relative risks, across occupations for example, which would allow us to evaluate the differences in the attributable fractions according to occupation. This point, which we referred to in the introduction, would allow us to add detail to existing French results on the differences in risk exposure by occupation, and in particular the higher levels of exposure experienced by those in the lessskilled occupations.

We have considered three types of illness here: cardiovascular and psychological diseases and MSDs. The evaluation in terms of attributable fractions is thus restricted to these three groups and certainly does not reflect a global estimation of the effect of job strain on overall morbidity and mortality. Job strain may well be a risk factor for other illnesses, thus affecting overall outcomes of morbidity (self-assessed health, quality of life, and so on). Equally, job strain may be linked with other unhealthy behaviours (such as smoking), which are themselves risk factors for various illnesses. As such, our estimations of attributable fractions under-estimate the impact of the risk factor in public-health terms. More generally, the calculation of attributable fractions is limited by the availability of data on relative risk in the epidemiological literature. If an association between a risk factor and an illness has been established in the literature but without a value for the relative risk this association cannot be used in our calculations.

The choice of the Karasek model of job strain to measure exposure to job stress is simplistic and will affect the estimation of the attributable fractions. We as a result consider exposure to job stress only in the light of this specific theoretical model: all other measures or types of job stress are ignored, even though there is no doubt that they are important (NDJABOuÉ et al., 2012, discuss three types of recent models). Our restriction to the Karasek model will probably lead to an under-estimation of the attributable fractions in terms of job stress. It is however very difficult to evaluate the size of this under-estimation as the different aspects of job stress are very likely correlated between themselves.

Our choice of the Karasek measure of job strain was a key criterion in determining the studies that we included in our literature review. In addition, job strain has only rarely been evaluated using the survey instrument recommended by KARASEK (1998) (the Job Content Questionnaire, or JCQ). As such, the number and wording of the survey items varies across the different studies. Equally, the recommendation to define job strain using the median levels of the job demands and decision latitude scores is not systematically followed. However, applying stricter selection criteria would have led to greater homogeneity but the retention of far too few studies. The resulting heterogeneity in the measure of job strain may well lead to greater imprecision in the estimates in some of the studies that we consider here.

The studies we review differ in a number of other ways. Even without considering the measure of job strain, the measure of the illness under consideration is also not always the same. With respect to cardiovascular disease, the source of the data differs from one article to another: hospital registers, national registers, hospital data, clinical diagnoses, and questionnaires. Regarding mental health, the evaluation is sometimes self-reported (using validated questionnaires) via the measure of symptoms (as in the GHQ, the CES-D and so on), or more rarely based on diagnostic interviews (the CIDI, for example). These two methods produce radically different evaluations, more symptomatology-oriented for the first and more clinical for the second, and therefore different estimated prevalences. Equally, as noted above, as MSDs are measured in a number of different ways (questionnaires, clinical diagnoses, and administrative data) and concern a variety of locations, the measures are far from standard across the different studies in the literature. Last, other sources of heterogeneity should be mentioned, referring to the different control variables that are used and the duration of the follow-up period. Given the number of different factors which vary from one study to another, it is difficult to come to any conclusion regarding the overall impact on the estimated attributable fractions, or to say which of these factors are likely the most important.

\section{Methodological Discussion of the Use of Attributable Fractions}

The calculation of attributable fractions that we have carried out here relied on the most classic formula, which is also that which is the most parsimonious in terms of data requirements. This formula is based on adjusted RR, and not on nonadjusted RR. This choice was guided by data availability, as non-adjusted RR data is rarer in the literature than are figures on adjusted RRs. This choice probably leads the attributable fractions to be under-estimated, as adjusted RRs are in general smaller than their non-adjusted counterparts. The difference between adjusted and non-adjusted RRs may be at least partly explained by controlling for variables which may be intermediaries between exposure and illness rather than real confounding variables. To cite just one example, controlling for 
high blood pressure (the same reasoning can be applied to other cardiovascular risk factors such as hypercholesterolemia, diabetes, and even unhealthy behaviours such as smoking and drinking) can lead to the under-estimation of the link between job strain and cardiovascular disease. High blood pressure is a well-known risk factor for cardiovascular disease, and we know that this risk rises with job strain. Rather than acting as a confounding factor, blood pressure should be considered here as an intermediary variable or, in other words, a biological mechanism which leads job strain to cause cardiovascular disease. Controlling for blood pressure then neutralises part of the real effect of job strain on illness, leading to under-estimated coefficients.

The different sources of heterogeneity can be suppressed as far as possible by the use of selection criteria for the research that is included in the literature review yielding the RR figures. But given the limited availability of relevant epidemiological data, it is difficult to guarantee that the RR data used in the estimations of attributable fractions be perfectly comparable. In the same spirit of homogeneity, the data on exposure prevalence used in the attributable fraction calculation should come from work which uses comparable methods, in terms of the instrument used to measure exposure and the duration of exposure considered. This requirement is not always easy to satisfy, which explains the need for national representative survey data which allow the accurate measurement of exposure to different health risk factors.

In general, attributable fractions imply a causal link between exposure and illness (even though this is not a necessary condition), which, in the domain of job stress, remains an open epidemiological question. Although the link between exposure and illness is easy to define via a test of statistical significance, the causal relationship is more difficult to prove in epidemiology and is based rather on a range of elements which suggest the causal nature of the relationship (BOUYER et al., 2010). The existence of a statistical link is of course a key element of any causal relationship. The strength of this statistical link is also important: the stronger is the relationship, the more likely is causality, and especially so when the biological mechanisms underlying the causal link have been identified. The fact that exposure has its own specific effect, independently of other known risk factors, reassures us that the relationship is not due to omitted confounding factors. A dose-response relationship allows us to go further by showing that the greater is exposure, the greater the risk of subsequent illness. Another pertinent point comes from the chronology of the events, as we do need to be able to show that exposure precedes the onset of illness. In epidemiology the accumulation of knowledge regarding an exposure-illness relationship is decisive in establishing the reliability, robustness and consistency of the link in question. The fact that the same relationship re-appears in a large number of different studies, across different countries and samples for example, reassures us as to its solidity. Last, the results of work on the biological mechanisms yielding a better understanding of the way in which risk exposure can lead to illness are very important in underlining the causality of the relationship.

Another way of demonstrating a causal relationship between a risk factor and health outcomes is to adopt an experimental rather than observational methodology. This experimental method is radically different to that which we have applied here. Instead of looking for the effects of a risk factor on individual health without changing the environment, this approach makes up a number of different groups that are comparable in every way, and then randomly varies the amount of risk exposure or treatment experienced by different individuals. Ideally, neither the participants nor the researchers know which individual has experienced which treatment until the end of the experiment (i.e. a double-blind trial). This approach of a randomised control trial is considered to be the most reliable in epidemiology in terms of establishing causal relationships.

This type of approach, apart from the fact that it is particularly difficult to implement in the domain of workplace health, can only be used to evaluate the positive effects of a treatment or intervention on individual health. For obvious ethical reasons, the negative effects of risk factors on individual health are evaluated using observational rather than experimental methods in epidemiology. The dialogue between epidemiology and economics regarding the use of experimental methods to establish causality has thus remained restricted. The recent and rapid development of experimental methods in economics over the past twenty years has mostly concerned work on individual decisions determining the behaviour of economic agents (DAVIS, HoLt, 1993; KAGEL, Rотн, 1995). Given the central place accorded to individual decision-making, very little experimental work has focussed on the link between job stress and individual health. Two exceptions can be pointed out. The recent study by FALK et al. (2011) analysed the effects of workplace injustice on employee heartbeat variability. In this laboratory experiment, a group of individuals, drawn randomly, are put in a situation of workplace injustice where earnings do not correspond to the quantity of work carried out (objective injustice) and/or where earnings are perceived as unjust by the individual (subjective injustice). The results revealed a positive significant relationship between a certain amount of injustice and heartbeat variability. Appealing to a large-scale natural experiment (not carried out in the laboratory), DE GRIP et al. (2012) analysed the effects of a drastic pension reform implemented in Holland in 2006 on worker mental health, distinguishing an experimental treatment group (the cohort of workers 
born in 1950) from a control group who were not affected by the reform (the cohort of workers born in 1949). Using data from a survey including the CES-D measure of mental health, a significant link was found between poor mental health and having experienced the pension reform.

These economic studies have produced results that are similar to those from the literature we reviewed on the link between job strain, on the one hand, and cardiovascular disease and mental health on the other. However, they cannot be compared directly due to differences in the definitions of both the risk factors and the health effects in the two literatures, and the radical difference in the methods employed in the experimental and non-experimental approaches. It is thus not easy to establish a range for the magnitude of the relationship between exposure and illness from the two literatures given these differences, even though the objective of the research is sometimes very similar.

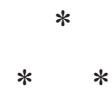

The estimation of the costs of diseases attributable to work-related factors such as job stress is a central issue in the debate over the priority of prevention programmes. Such analyses can also help to provide an estimate of the social cost of workplace risks by appealing to data on the costs of various illnesses established in the health economics literature. The attributable fractions estimate used here has the advantage of being based on data that is available (exposure prevalence and relative risks) and of being simple to apply. Even so, any use that is made of the results has to take into account the inherent methodological limitations of the estimations.

The calculation of attributable fractions requires robust and consistent data on exposure prevalence and relative risks, which assumes that sufficient resources are dedicated to large-sample epidemiological and etiological prospective surveys with accurate measures of exposure. Such surveys, incorporated into large-scale national surveys, would represent a substantial contribution to the advancement of our knowledge in this respect, by providing high-quality exposure data and etiological data including both illness outcomes and confounding factors in the context of a prospective analysis. The future estimation of attributable fractions should also consider alternative measures of job stress to that of Karasek. However, the difficulties that we have outlined above in the analysis of attributable fractions for job strain in France may be exacerbated for other types of work-related psychosocial risk factors, as these are all relatively more recent than those contained in the Karasek model.

Funding Acknowledgement: Agence nationale pour la recherche (ANR), Plan santé-travail santéenvironnement (work- and environment-related health programme), Convention n ${ }^{\circ}$ 05-9-30.

\section{Bibliography}

Aldabe B., et al. (2011), "Contribution of material, occupational, and psychosocial factors in the explanation of social inequalities in health in 28 countries in Europe", Journal of Epidemiology and Community Health, vol. 65, $\mathrm{n}^{\circ} 12$, pp. 1123-31.

Askenazy P. (2005), Les désordres du travail. Enquête sur le nouveau productivisme, Paris, Le Seuil.

Barnay T., Sauze D., Sultan-Taïeb H. (2010), «La santé au travail: une préoccupation multiforme pour les économistes", Revue française des affaires sociales, $\mathrm{n}^{\circ} 4$, pp. 7-25.

Bejean S., Sultan-Taïeb H. (2005), "Modeling the economic burden of diseases imputable to stress at work", European Journal of Health Economics, vol. 50, $\mathrm{n}^{\circ} 1$, pp. 16-23.

BeLKIc K. L., et al. (2004), "Is job strain a major source of cardiovascular disease risk?", Scandinavian Journal of Work, Environment and Health, vol. 30, n 2, pp. 85-128.

Benichou J., et al. (1998), « Population attributable risk of renal cell cancer in Minnesota », American Journal of Epidemiology, vol. 148, $\mathrm{n}^{\circ}$ 5, pp. 424-30.
BondE J. P. (2008), “Psychosocial factors at work and risk of depression: a systematic review of the epidemiological evidence", Occupational and Environmental Medicine, vol. $65, \mathrm{n}^{\circ}$ 7, pp. 438-45.

Bongers P. M., Kremer A. M., Ter Laak J. (2002), “Are psychosocial factors, risk factors for symptoms and signs of the shoulder, elbow, or hand/wrist? A review of the epidemiological literature", American Journal of Industrial Medicine, vol. 41, n ${ }^{\circ}$, pp. 315-42.

Bouyer J, et al. (2010), Épidémiologie: principes et méthodes quantitatives, Paris, Lavoisier.

Daubas-Letourneux V. (2008), «Produire des connaissances en santé au travail à l'échelle régionale : le signalement des maladies à caractère professionnel dans les Pays de la Loire», Revue française des affaires sociales, $\mathrm{n}^{\circ} 2-3$, pp. 213-235.

Davis D., Holt C. (1993), Experimental economics, Princeton, Princeton University Press.

De Grip A., Lindeboom M., Montizana R. (2012), "Shattered dreams: the effects of changing the pension 
system late in the game", The Economic Journal, vol. $122, \mathrm{n}^{\circ} 559$, pp. 1-25.

De Lange A. H., et al. (2003), "The very best of the millennium: longitudinal research and the demandcontrol-(support) model", Journal of Occupational Health Psychology, vol. 8, $\mathrm{n}^{\circ}$ 4, pp. 282-305.

DÉRIOT G. (2010), Rapport d'information fait au nom de la commission des affaires sociales par la mission d'information sur le mal-être au travail, Sénat, ${ }^{\circ}$ 642, document consultable sur le site http:/www.senat.fr/rap/ r09-642-1/r09-642-11.pdf

DiricQ N. (2008, 2011), Rapport de la commission instituée par l'article L. 176-2 du Code de la Sécurité sociale, Paris, ministère de la Santé, de la Jeunesse, des Sports et de la Vie associative.

Driscoll T., et al. (2005), "Review of estimates of the global burden of injury and illness due to occupational exposures", American Journal of Industrial Medicine, vol. 48, n 6, pp. 491-502.

FALK A., et al. (2011), "Cardiovascular consequences of unfair pay”, CEPR Discussion Paper, WP DP8463.

Gollac M., Bodier M. (2011), Mesurer les facteurs psychosociaux de risque au travail pour les maîtriser, rapport du Collège d'expertise sur le suivi des risques psychosociaux au travail, Paris, ministère du Travail, de l'Emploi et de la Santé, 223 p. Consultable sur le site http://www.ladocumentationfrancaise.fr/var/storage/ rapports-publics/114000201/0000.pdf

Gollac M., Volkoff S. (2006), «La santé au travail et ses masques», Actes de la recherche en sciences sociales, $\mathrm{n}^{\circ} 163$, pp. 4-17.

GuIGNON N. (2001), «Enquête SUMER 2001-2002 (Surveillance médicale des risques professionnels) ", Documents pour le médecin du travail, $\mathrm{n}^{\circ} 86$, pp. 161-165.

Jeanrenaud C., Soguel N. (1999), Valuing the cost of smoking: assessment methods, risk perception and policy options, Dordrecht, Kluwer Academic Publishers Group.

Kagel J. H., Roth A. E. (1995), The handbook of experimental economics, Princeton, Princeton University Press.

KARASEK R. (1979), “Job-demands, job decision latitude, and mental strain: implications for job redesign", Administrative Science Quarterly, vol. 24, $\mathrm{n}^{\circ}$ 2, pp. 285-308.

Karasek R., Theorell T. (1990), Health work stress, productivity and reconstruction of working life, New York, Wiley.

KARASEK R., et al. (1998), “The Job Content Questionnaire (JCQ): an instrument for internationally comparative assessments of psychosocial job characteristics", Journal of Occupational Health Psychology, vol. 3, n 4, pp. 322-55.

Kasbi-Benassouli V., et al. (2005), Confrontation des cancérogènes avérés en milieu de travail et des tableaux de maladies professionnelles, Saint-Maurice, Institut de veille sanitaire (InVS).

KIVIMÄKı M., et al. (2006), "Work stress in the etiology of coronary heart disease: a meta-analysis", Scandinavian Journal of Work, Environment and Health, vol. 32, n 6 , pp. 431-42.

Kopp P., Fenoglio P. (2003), "Social cost of drugs in France", European Addiction Research, vol. 3, $\mathrm{n}^{\circ} 1$, pp. 1-52.

Lachmann H., Larose C., Penicaud M. (2010), Bien-être et efficacité au travail-10 propositions pour améliorer la santé psychologique au travail, Paris, rapport au Premier ministre.

LaMontagne A. D., et al. (2008), "Job strain -attributable depression in a sample of working Australians: assessing the contribution to health inequalities", BMC Public Health, vol. $8, \mathrm{n}^{\circ} 181$.

Levi L., Lunde J. P. (1996), A model for assessing the costs of stressors at national level: socio-economic costs of work stress in two EU member states, Dublin, European Foundation for the Improvement of Living and Working Conditions.

LEVIN M. L. (1953), "The occurrence of lung cancer in man", Acta Unio Int Contra Cancrum, vol. 9, $\mathrm{n}^{\circ} 3$, pp. 531-41.

Ndjaboué R., Vézina M., Brisson C. (2012), «Effets des facteurs psychosociaux au travail sur la santé mentale. Une revue de littérature des études prospectives portant sur trois modèles émergents », Travail et emploi, $\mathrm{n}^{\circ} 129$, pp. 23-34.

Nelson D., et al. (2005), "The global burden of selected occupational diseases and injury risks: methodology and summary", American Journal of Industrial Medicine, vol. $48, \mathrm{n}^{\circ} 6$, pp. 400-18.

NiedHAMmer I. (2011), «Facteurs psychosociaux au travail : modèles et concepts en épidémiologie», in Stress au travail et santé. Situation chez les indépendants, Paris, Éditions Inserm, coll. «Expertise collective», pp. 25-46.

Niedhammer I. et al. (2007), «Exposition aux facteurs psychosociaux au travail du modèle de Karasek: étude méthodologique à l'aide de l'enquête nationale SUMER », Travailler, $\mathrm{n}^{\circ}$ 17, pp. 47-70.

Niedhammer I., Bourgkard E., Chau N. (2011), "Occupational and behavioural factors in the explanation of social inequalities in premature and total mortality: a 12.5-year follow-up in the Lorhandicap study", European Journal of Epidemiology, vol. 26, n 1, pp. 1-12.

Niedhammer I., et al. (2006), «Propriétés psychométriques de la version française des échelles de la demande psychologique, de la latitude décisionnelle et du soutien social du "Job Content Questionnaire" de Karasek: résultats de l'enquête nationale SUMER », Santé publique, vol. 18, n 3, pp. 413-27. 
Niedhammer I., et al. (2008), "The contribution of occupational factors to social inequalities in health: findings from the national French SUMER survey", Social Science and Medicine, vol. 67, n 11, pp. 1870-81.

Niedhammer I., et al. (2008), "Study of the validity of a job-exposure matrix for psychosocial work factors: results from the national French SUMER survey", International Archives of Occupational and Environmental Health, vol. $82, \mathrm{n}^{\circ} 1$, pp. 87-97.

Nurminen M., Karjalainen A. (2001), “Epidemiologic estimate of the proportion of fatalities related to occupational factors in Finland", Scandinavian Journal of Work Environment and Health, vol. 27, $\mathrm{n}^{\circ}$ 3, pp. 161-213.

Parent-Thirion A., et al. (2007), Fourth European Working Conditions Survey, Luxembourg, European Foundation for the Improvement of Living and Working Conditions.

Ramaciotti D., Perriard J. (2001), Les coûts du stress en Suisse, Genève, Ergorama, université de Neuchatel.

Roquelaure Y., et al. (2005), «Surveillance en population générale du syndrome du canal carpien dans le Maineet-Loire en 2002 et $2003 »$, Bulletin épidémiologique hebdomadaire, $\mathrm{n}^{\circ}$ 44-45, pp. 224-226.

Rothman K., Greenland S. (1997), Modern epidemiology, New York, Lippincott-Raven, Second Edition.

SERrier H., et al. (2009), "Quelles sont les difficultés méthodologiques de l'évaluation des politiques publiques de prévention en santé au travail? ", in Barnay T., Legendre F., (Eds.), Emploi et politiques sociales, Paris, L'Harmattan, pp. 43-56.

Siegrist J., et al. (2004), "The measurement of effortreward imbalance at work: European comparisons", Social Science and Medicine, vol. 58, n 8, pp. 1483-99.

SiEGrist J., et al. (1990), "Low status control, high effort at work and ischemic heart disease: prospective evidence from blue-collar men", Social Science and Medicine, vol. $31, \mathrm{n}^{\circ} 10$, pp. 1127-34.
Stansfeld S., Candy B. (2006), "Psychosocial work environment and mental health: a meta-analytic review", Scandinavian Journal of Work, Environment and Health, vol. 32, n 6, pp. 443-62.

Sultan-Taї̈B H., etal. (2011), "Fractions of cardiovascular diseases, mental disorders, and musculoskeletal disorders attributable to job strain in France", International Archives of Occupational and Environmental Health, vol. 84, n 8 , pp. 911-925.

ThéBaud-Mony A. (2007), Travailler peut nuire gravement à votre santé: sous-traitance des risques, mise en danger d'autrui, atteintes à la dignité, violences physiques et morales, cancers professionnels, Paris, La Découverte.

ThéBAud-Mony A. (2006), «Histoires professionnelles et cancer», Actes de la recherche en sciences sociales, $\mathrm{n}^{\circ} 163$, pp. 18-31.

UсніуAма S, et al. (2005), "Job strain and risk of cardiovascular events in treated hypertensive Japanese workers: hypertension follow-up group study", Journal of Occupational Health, vol. 47, $\mathrm{n}^{\circ} 2$, pp. 102-111.

VÉzina M., et al. (2011), Enquête québécoise sur des conditions de travail, d'emploi, et de santé et de sécurité du travail (EQCOTESST), Montréal, Institut de recherche Robert-Sauvé en santé et sécurité du travail Institut national de santé publique du Québec et Institut de la statistique du Québec.

Volkoff S. (2008), «La recherche et l'action en santé au travail. Idées ancrées et nouveaux obstacles», Revue française des affaires sociales, $\mathrm{n}^{\circ}$ 2-3, pp. 13-17.

WAlter S. D. (1998), “Attributable risk in practice", American Journal of Epidemiology, vol. 148, $\mathrm{n}^{\circ}$, pp. 411-3.

Wilson P. D., et al. (1998), "Attributable fraction for cardiac malformations", American Journal of Epidemiology, vol. 148, n 5, pp. 414-23. 